\title{
Transdisciplinarity in Evaluating the Health Conditions of Institutionalized Elderly Persons in Bauru, São Paulo, Brazil
}

José Roberto de Magalhães Bastos, ${ }^{1 *}$ Andrea Mendes FIGUEIRED0, ${ }^{2}$ Cristina do Espírito SANTO, ${ }^{3}$ Patrícia Ribeiro Mattar DAMIANCE, ${ }^{4}$ Thaisa Rino de Freitas Coelho, ${ }^{5}$ Leticia de Azevedo LEITE, ${ }^{6}$ Roosevelt da Silva BASTOS, ${ }^{7}$ Samir Paiva do Espírito SANTO, ${ }^{8}$ Magali de Lourdes CALDANA ${ }^{9}$

${ }^{1}$ Professor, University of São Paulo, Bauru, Brazil

${ }^{2}$ Assistant Professor, University of Sagrado Coração, Bauru, Brazil

${ }^{3}$ Assistant Professor, UNIESP, Bauru, Brazil

${ }^{4}$ Assistant Professor, IMESA-FEMA, Assis, Brazil

${ }^{5}$ Associate Professor-UNIP, Bauru, Brazil

${ }^{6}$ Master student of Public Health, University of São Paulo, Bauru, Brazil

${ }^{7}$ Associate Professor, University of São Paulo, Bauru, Brazil

${ }^{8}$ Master student of Public Health, University of São Paulo, Bauru, Brazil

${ }^{9}$ Associate Professor, Bauru, Brazil

\begin{abstract}
The main aim of the research developed and described here was to record and evaluate-in the light of the concept of transdisciplinarity-the conditions of health and functional capacity of institutionalized elderly persons in Bauru, a city with 400,000 inhabitants, situated close to the centre of the state of São Paulo, Brazil. A descriptive and exploratory field research was conducted with diverse objects of research and methodologies, considering the fields of Dentistry, Nursing, Physical Therapy, Biomedicine and Speech Therapy. The Government effort in Brazil must be placed on record to make it possible to understand therapid growth of its elderly population, its consequences and needs, with the aim of greatly enhancing attention to their quality of life, compatible with the expectations of the population and authorities in all fields of Brazilian health care.
\end{abstract}

Keywords: Aged, Transdisciplinary research, Health status

\section{Key Question Summary}

\section{What is known about the topic?}

The principles of transdisciplinarity can be applied to obtain consistent knowledge about the reality of the day-by-day of the institutionalized elderlies, mainly in Brazil, and respective quality of life.

\section{What does this paper add?}

The knowledge about related aspects with the institutionalized elderly health must allow planning the measures to be taken with the aim to implant policies to become possible improving, in the significative way, the quality of live and the expectative of life of the elderlies.

\begin{tabular}{|l|l|}
\hline \hline Quick Response Code: & *Corresponding author: José Roberto de Magalhães Bastos, Professor, University of São Pau- \\
lo, Alameda Dr. Octávio Pinheiro Brisolla, 9-75, Jardim Brasil, Bauru/SP, 17012-901, Brazil \\
Received: 12 May, 2021 \\
Published: 14 June, 2021
\end{tabular}




\section{What are the implications for practioners?}

The collected data and the fundaments of the transdisciplinarity in health, present the aim to influence, strongly, on the management related with health, as individual as collective, of the institutionalized elderlies. We hope, too, contribute to decrease the expenses and add better efficiency to the system.

\section{Introduction}

The discussions surrounding aspects such as complexity, interdisciplinarity, multidisciplinarity and transdisciplinarity are of transcendent importance to this "atypical" scientific field of Collective Health-considering the following media: theoretical, pragmatic, quantitative, qualitative, biological, social, universal, and Brazilian. In this sense, any attempt to undertake critical treatment of these aspects is always very welcome, especially when this is done by a researcher who has previously been noted for his/her intellectual restlessness, and therefore, for an acute capacity to foster reflection and debate".

The interest here is to demonstrate the complexity of working with research by applying a context of INNOVATIVE "transdisciplinaridade", acceptable by some within the Academy, and unacceptable by others within the same Academy. New ideas are known to normally incite the Academic Community to an initial stance of non-acceptance. What is desired, however, within the concepts of Collective Health, is the proposal of new fields, objectives, paradigms in the sense of improving public and private systems with regard to the health of the population. The results - depending on the innovative proposals-will not always please those who are used to dealing with conventional models, which is understandable on the one hand, and on the other, by muzzling new concepts that arise, such as that of transdisciplinarity (that is not all that new, since it concerns something that dates back as far as the 1970s), which is inadmissible..$^{2-4}$

These assertions were applied with the purpose of evaluating the health conditions of elderly residents who live in public and private institutions for the elderly on a long term basis (places traditionally known as old-age homes) in a Brazilian municipality (with around 400.000 inhabitants at the end of the year 2018), situated in the heart of the state of São Paulo. The aims comprised the ideals of transdisciplinarity, with the intention of contributing to the National Policy for the Elderly in force in Brazil, in particular, by seeking to evaluate their oral health, speech-language (pathology) therapy conditions, and general health conditions. These wereanalysed by having laboratory exams performed, assessing their consumption of medications and control of these within the institutions, taking into consideration the consequences of medications on the quality of life of the institutionalized elderly. Professors and research professionals from five areas of knowledge, namely Dentistry, Speech Therapy, Biomedicine, Nursing and Physical Therapy, were involved in the research.

\section{Aims}

To evaluate the general health conditions of institutionalized elderly persons in Bauru, São Paulo, Brazil, from the perspective of contributing to the Strategic Planning in Health and to the National Policy for the Elderly. To achieve these objectives, the following issues were considered: oral health, conditions emanating from physical therapy, nutritional conditions, laboratory exams using simple and low cost methodologies, and procedures in the area of Speech Therapy and pathologies. Also considered were mental disturbances, with emphasis on depression, a common condition in the elderly; and continual consumption of medications and their consequences on the quality of life.

\section{Methods}

The research, based on transdisciplinarity, was appreciated and approved by the Research Ethics Committee of the Bauru Dental School, University of São Paulo, Brazil, Protocol No. 44904315.8.0000.5417. The project was developed with the support of FAPESP-Foundation to Support Research in the State of São Paulo, Brazil (Process No. 2013/21205-0). ${ }^{5}$ Elderly persons from four Institutions (two public and two private) distributed among 4 geographical regions of Bauru, representing the North, South, East and West were selected by draw, and participated in the project. All the participants signed the TFIC (Term of Free and Informed Consent) in accordance with Brazilian legislation, ${ }^{6}$ in which the ethical aspects are described for the information of participants, secrecy,

Confidentiality,possible risks and damages, indemnities for damages, filing charges or complaints. This included explanations about the aims of the research, those of each researcher, participation of the family and/or person responsible for each institution. The procedures and interventions, by area of activity of the team, were described in detail and the Time Schedule of Intervention, primary and secondary data collection were agreed with the technicians in charge. Before any activity whatever, the nurse in charge, within the Group, arranged schedules for the participants who had any doubt to receive explanations about their possible doubts.

As regards the sample, the number of participants in each area of knowledge was variable, specifically because of excluding elderly persons who did not fit into the specific criteria. The total number of participants was 146 elderly persons, age equal to or older than 60years; with preserved capacity for communication; favourable anatomic and health conditions for blood collection, and who agreed to sign the TFIC. In total 74 elderly women and 72 elderly men were registered; of whom $40.0 \%$ (58) were 60-69years of age; $34 \%$ (50) aged $70-79$ and $26.00 \%$ (38) aged 80 years; or older. of the elderly $69.5 \%$ were white and $20.0 \%$ black. The remaining $11.5 \%$ were considered yellow or dark (skin colour).

\section{Institutions Where the Elderly Lived on A Long-Term Ba- sis}

The quest for quality of life during the aging process must be emphasized, whether in senescence or in senility, and individuals must be considered social human beings interacting with their environment. Active aging comes into play and undergoes a process of optimizing the opportunities of enjoying/experiencing health, participation and safety. This makes it necessary for the elderly to assume new perspectives of life, as subjects of their own history, 
and society must accept this new challenge. It concerns a trajectory that cannot be considered easy for either of the two sides, and demands changes in the population in general, enhancing interpersonal relations, assuming the Brazilian demographic transition, and seeking policies and actions that envisage improved quality of life for the elderly. ${ }^{7}$ Considering population aging in Brazil and worldwide, important conquests, which gradually were and are being implemented and perfected, have been reached in spite of the existing obstacles to their full implementation? In 2006, the National Day of the Elderly was implemented, and various Federal Laws were created and implemented the National Policy for the Elderly, based on deduction of income tax, cooperating with making feasible the programs directed towards the elderly. ${ }^{7}$ The different professionals in the field of health have most clearly adhered to these endeavours to improve the quality of life of the cited population and for development of the National Policy for the Elderly in Brazil. The multidisciplinary approach in social assistance must act with focus on the quality of life of the users attended. Professionals of different areas have offered attendance cantered on the user, mainly taking care to ensure that social relations remain healthy and balanced. The public services must also guarantee the provision of information about the rights of the elderly population attended.

\section{Socioeconomic Levels of Users}

Generally speaking, the elderly were classified as being of the low, or inferior low social class, as they were almost completely dependent on the ILPIs, particularly on the care offered by SUS,(Sistema Único de Saúde-Public Health System- Brazil) the free-of-charge public system with reference to health in Brazil. ${ }^{8}$ Of the 146 elderly persons participating in the study, 118 (81.0\%) used the Brazilian public service, and only $28(19.0 \%)$ also counted on some private resource.

\section{Results and Discussion}

\section{The rapid growth of the elderly population in Brazil and} worldwide-what should be done?

Dentistry: To be considered an elderly person, Brazilians must be of a certain age, according to national legislation; they must be 60 years old or older, ${ }^{9}$ having therefore, been born in the second half of the decade of the 1950s and onwards. This is a population that has suffered severe aggression by dental caries disease and that has-over the years-become edentulous. This fact was proved in this research. The mean DMFT index of the elderly examined was around 28 or higher, extremely high. Thus there was a need for placement of complete dentures in those who did not wear them - a number exceeding 40-an alarmingly high number. The remaining teeth were in an extremely poor state of conservation, frequently presenting serious periodontal problems, according to a publication of the World Health Organization. ${ }^{10}$

Biomedicine: The records showed that the elderly (8.90\%) consumed alcoholic beverages, although in light doses, within the institution itself, normally during festivities. Moreover, 32.39\% routinely made use of tobacco; however, the majority of them were not continuous users of alcohol or tobacco. "Mental disturbances" were detected in 74 elderly persons, and arterial hypertension in 43 (29.40\% of the sample), mainly of the female sex $(61.00 \%)$, between the ages of 70 and 79 years. Diabetes Mellitus was present in 38 elderly persons ( $26.00 \%$ of the sample), the majority in the male sex, at the age from 60-69 years. There were various factors of risk for health, with anaemia being outstanding (22.60\%) however; in only 2 cases this represented serious or moderate anaemia; increased total cholesterol (27.40\%); triglycerides (23.30\%); HDL $(37.00 \%)$ and LDL $(30.15 \%)$. With regard to the record of $\mathrm{BMI}^{11}$ the majority of elderly persons had normal weight $(\mathrm{N}=107)$, with 21 showing low weight and 18 overweight or obese (only 2 elderly persons).

Physical Therapy: Various visits were made to the 04 (four) Institutions that participated in the research; various activities were performed there, such as measuring the skin folds, recording weight and height. The functional capacity of the elderly was evaluated by recording physical abilities by means of tests that assessed gait, balance and muscle strength (Tug, one-legged support, Tandem Walk and muscle strength tests. ${ }^{12-16}$ Relative to BMI (WHO, 1998) $77.00 \%$ of the elderly male and $69.00 \%$ of the female sex were found to fit into the range of normality. There was low weight among 8 elderly men and 13 women. As regards overweight, this was recorded in 8 men and 8 women, totalling $11.00 \%$ of the participants ( $\mathrm{n}=146)$; only 2 elderly persons were considered obese, both were of the female sex (1.30\%). A degree of dependence was found in the elderly, resulting in greater lack of balance, deficient gait and reduced muscle strength, leading to higher risk of falling. Thus, it is necessary to offer technical and logistic support to improve the functional capacity and daily activities of the elderly at the institutions where they were found, with consequent improvement in their quality of life. ${ }^{17}$

Nursing: The activities developed in the field of nursing allowed the main data to be recorded, mainly with reference to the consumption of medications by the institutionalized elderly persons. The research took transdisciplinarity into consideration; as was the case in all the areas under study, this was considered descriptive and exploratory field research. For data collection, a questionnaire was used, with open and closed questions about health, consumption and rational use of medications. At the institutions, medication treatment was managed by health professionals and carers. The elderly consumed over 5 different medications daily, with $50 \%$ of them ingesting over 10 pills per day. The oral administration pathway was predominantly used for offering the drugs. There were no institutional guidelines for identification, intervention and notification of adverse events linked to medication consumption, and their rational use was not discussed among those involved in the production of health and care. Unfortunately, it was observed that the elderly did not manage their care; they presented associated diseases; made use of polypharmacy and were subject to risk for medicamentous interaction; the therapeutic guidelines relative to the rational use of medications and management of adverse reactions werenot observed; analysis of medications consumed by the elderly, particularly those institutionalized, has the potential to reveal the references used for care and self-care in chronic health 
conditions, as well as observance of therapeutic guidelines in the assistance provided to elderly persons.

Speech-Language Therapy: Data was collected by application of three questionnaires. The first questionnaire was about the cognitive function of the elderly; the second, about the presence and degree of depression, and the third, about the speech-language pathology aspects. Those excluded were individuals who refused to sign the TFIC, and those who presented insufficiently preserved cognition that could compromise the faithfulness of the replies in the questionnaires, namely: The Beck Depression Inventory and Speech-language pathology-related aspects, evaluated by the Mini-Mental State Exam (MMSE). ${ }^{18,19}$ The elderly presented no severe depression $(0.00 \%)$. Moderate to Severe depression was found in $14.30 \%$ of the sample. Of the elderly, $28.60 \%$ had light/moderate depression and $57.10 \%$ presented no/minimal depression. Relative to Speech-language pathology, $35.70 \%$ reported no complaints. For those who presented single or multiple complaints, $35.70 \%$ reported problems with voice; $28.60 \%$, language; $14.30 \%$, orofacial motricity; $28.65 \%$, swallowing, and the large majority, $57.10 \%$, had hearing problems.

It must be recorded here that the researcher responsible for the activities in the speech-language pathology area, Head of the Department of Speech-Language Therapy, of the University of São Paulo, in Bauru, State of São Paulo, was invited, and worked actively in the Ministry of Health in Brasilia, Federal Capital, to elaborate the guidelines of attention to rehabilitation of the elderly in Brazilian territory, in accordance with the goals of the "Sistema Único de Saúde" (Brazilian national health service) (SUS), with the final document at the stage of publication.

\section{Conclusion}

Our main aims here were to demonstrate the complexity of working with research by applying a context of INNOVATIVE "transdisciplinaridade", acceptable by some within the Academy, and unacceptable by others within the same Academy. New ideas are known to normally incite the Academic Community to an initial stance of non-acceptance. When working with a modern approach to Collective Health, however, it is necessary to propose of new fields, objectives, paradigms in the sense of improving public and private systems with regard to the health of the population. The results, according to the philosophy of transdisciplinarity, will not always please those who are used to dealing with conventional models, which is understandable on the one hand, and inadmissible on the other; because the mandatory traditional model muzzles new concepts that arise and offers the International Scientific Community a set of information that supersedes the strict tests of scientific knowledge.

The conditions under which the research was developed, allowed the authors to observe that five areas of health were used. In addition to the Chief Researcher, Full Professor of Collective Health of the University of São Paulo Brazil, the researchers, all of whom are doctors with wide experience in their areas of professional activities (as listed below) also participated: Dentistry, Nursing, Physical
Therapy, Biomedicine and Speech-Language (Pathology) Therapy. All of them endeavoured to fulfil their responsibilities, considering that work in the field is clearly arduous and complex at all times. Collecting data with reference to institutionalized elderly persons at public and private institutions was, therefore, shown to be a task replete with difficulties. Nevertheless, the research was conducted as planned, after being approved by the foundation for support to research in the state of São Paulo - FAPESP (Fundação de Apoio à Pesquisa no Estado de São Paulo-Process No. 2013/21205-0).

Considering the data presented during the course of the text of the present study, the authors were able to add to the conclusions that in the light of transdisciplinarity, the activities were fully carried out, and have brought important practical contributions to the Brazilian health policies,specifically considering the elderly population. The conditions observed in the Institutions for the elderly in Bauru, who lived in these public and private institutions on a long term basis, allowed the authors to observe failures in the organizational structure in all the areas under study and in conjunction with each other. These were reasons for later meetings with the leaders of the ILPIs, for the purpose of reporting the problems detected and contributing to improvement of the systems in progress, while also seeking to observe the limitations inherent to a research with a scope as broad as it was in the present study.

\section{Acknowledgments}

None.

\section{Funding}

FAPESP/USP/São Paulo/Bauru/Brazil.

\section{Conflict of Interest}

Author declares that there is no conflict of interest.

\section{References}

1. Ayres JRCM. Deve-se definir transdisciplinaridade? Ciência e Saúde Coletiva. 1997;11(1-2):36-38.

2. Bernstein JH. Transdisciplinarity: a review of its origins, development and current issues. Journal of Research Practice. 2015;11(1).

3. Choi BC, Pak AW. Multidisciplinarity, interdisciplinarity and transdisciplinarity in health research, services, educational and policy. Definitions, objectives and evidence of effectiveness. Clin Invest Med. 2006;29(6):351-364.

4. Van Bewer V. Transdisciplinarity in health care: a concept analysis. Nurs Forum. 2017;52(4):339-347.

5. FAPESP, Fundação de Amparo à Pesquisa do Estado de São Paulo, (Processo no.2013/21205-0) São Paulo, Brazil. 2013.

6. Brazil, 2012. Resolução no 466, CNS, 2012 Ministério da Saúde.

7. Damasceno RJ, Favoretto NC, Figueiredo AM. Envelhecimento ativo na ótica do ser biopsicossocial. In Caldana ML, Bastos JR M, Saúde do idosocuidados multiprofissionais na senilidade e senescência (pp 34-41), Book Toy, Ribeirão Preto, São Paulo, Brazil. 2015.

8. L8080, Brazil, 1990-Lei Federal no 8.080, Brazil; 1990.

9. Brazil. Ministry of Health. Statute of the Elderly/Ministry of Health. 2ed. rev-Brasília: Publisher of the Ministry of Health; 2009.

10. WHO. Oral Health Surveys: basic methods. 5 ed. Geneva: WHO; 2013. 
11. WHO. Obesity: preventing and managing the global epidemic. Report of a WHO consultation, Geneva, 3-5 Jun 1997. Geneva: World Health Organization, 1998. (WHO/NUT/98.1.)

12. Podsiadlo D, Richardson S. The timed "Up \& Go": a test of basic functional mobility for frail elderly persons. J Am Geriatr Soc. 1991;39(2):142-148.

13. Shumway-Cook A, Brauer S, Woollacott M. Predicting the probability for falls in community-dwelling older adults using the timed up of go test. Physical therapy. 2000;80(9):896-903.

14. Gustafson AS, Noaksson ACG, Kronhed ACG. Changes in balance performance in physically active elderly people aged 73-80. Scand J Rehabil Med. 2000;32(4):168-172.

15. Chantanachai T, Pichayongdees, Jalayondeja C. Fall prediction in thai elderly with timed up and go and tandem walk test; a cross-sectional study. J Med Assoc Thai. 2014;97 Suppl 7:S21-25.
16. Cohen, Helen S, Stitz, et al. Tandem walking as a quick screening test for vestibular disorders. Laryngoscope. 2018;128(7):1687-1691.

17. Freitas ERFS, Rogerio FRPG, Yamacita CM, et al. Does usual practice of physical activity affect balance in elderly women? Fisioter. Mov. 2013;26(4):813-821.

18. Bertolucci PHF, Brucki SMD, Campacci SR, et al. O mini-exame do estado mental em uma população geral: impacto da escolaridade. Arq Neuropsiquiatr.1994;52(1):1-7.

19. Folstein MF, Folstein SE, McHugh PR. Mini-mental state: a practical method for grading the cognitive state of patient for the clinician. $J$ Psychiatric Res. 1975;12(3):189-198. 